\title{
Extraction of Plutonium From Spiked INEEL Soil Samples Using the Ligand-Assisted Supercritical Fluid Extraction (LA-SFE) Technique
}

\author{
Robert V. Fox \\ Chemical and Materials Processes Department \\ Idaho National Engineering and Environmental Laboratory \\ P.O. Box 1625 \\ Idaho Falls, Idaho 83415 \\ (208) 526-7844 \\ Bruce J. Mincher \\ Radiation Physics Products Department \\ Idaho National Engineering and Environmental Laboratory \\ P.O. Box 1625 \\ Idaho Falls, Idaho 83415 \\ (208) 533-4449 \\ Robert G. G. Holmes \\ British Nuclear Fuels, Inc. \\ 1970 East $17^{\text {th }}$ St., Suite 207 \\ Idaho Falls, Idaho 83404 \\ (208) 524-8484 \\ Published August 26, 1999 \\ A Summary Report of Phase I Activities for the \\ Work For Others Project\# 98-820 \\ Prepared for the U.S. Department of Energy, Idaho Operations Office
}




\section{DISCLAIMER}

This report was prepared as an account of work sponsored by an agency of the United States Government. Neither the United States Government nor any agency thereof, nor any of their employees, makes any warranty, express or implied, or assumes any legal liability or responsibility for the accuracy, completeness, or usefulness of any information, apparatus, product or process disclosed, or represents that its use would not infringe privately owned rights. References herein to any specific commercial product, process, or service by trade name, trademark, manufacturer, or otherwise, does not necessarily constitute or imply its encorsement, recommendation, orfavoring by the United States Government or any agency thereof. The views and opinions of authors expressed herein do not necessarily state or reflect those of the United States Government or any agency thereof. 


\section{DISCLAIMER}

Portions of this document may be illegible in electronic image products. Images are produced from the best available original document. 


\begin{abstract}
In order to investigate the effectiveness of ligand-assisted supercritical fluid extraction for the removal of transuranic contamination from soils an INEEL silty-clay soil sample was obtained from near the RWMC area and subjected to three different chemical preparations before being spiked with plutonium. The spiked INEEL soil samples were subjected to a sequential aqueous extraction procedure to determine radionuclide partitioning in each sample. Results from those extractions demonstrate that plutonium consistently partitioned into the residual fraction across all three INEEL soil preparations whereas americium partitioned $73 \%$ into the iron/manganese fraction for soil preparation $\mathrm{A}$, with the balance partitioning into the residual fraction. Americium partitioned $80 \%$ into the iron/manganese fraction for soil preparation $\mathrm{B}$, with $10 \%$ partitioning into the organic fraction and the balance partitioning into the residual fraction. Americium partitioned $77 \%$ into the iron/manganese fraction for soil preparation $\mathrm{C}$, with $22 \%$ in the organic phase and the balance in the carbonate fraction. Plutonium and americium were extracted from the INEEL soil samples using a ligand-assisted supercritical fluid extraction technique. Initial supercritical fluid extraction runs produced plutonium extraction efficiencies ranging from $14 \%$ to $19 \%$. After a second round wherein the initial extraction parameters were changed, the plutonium extraction efficiencies increased to $60 \%$ and as high as $80 \%$ with the americium level in the post-extracted soil samples dropping near to the detection limits. The third round of experiments are currently underway. These results demonstrate that the ligand-assisted supercritical fluid extraction technique can effectively extract plutonium from the spiked INEEL soil preparations.
\end{abstract}




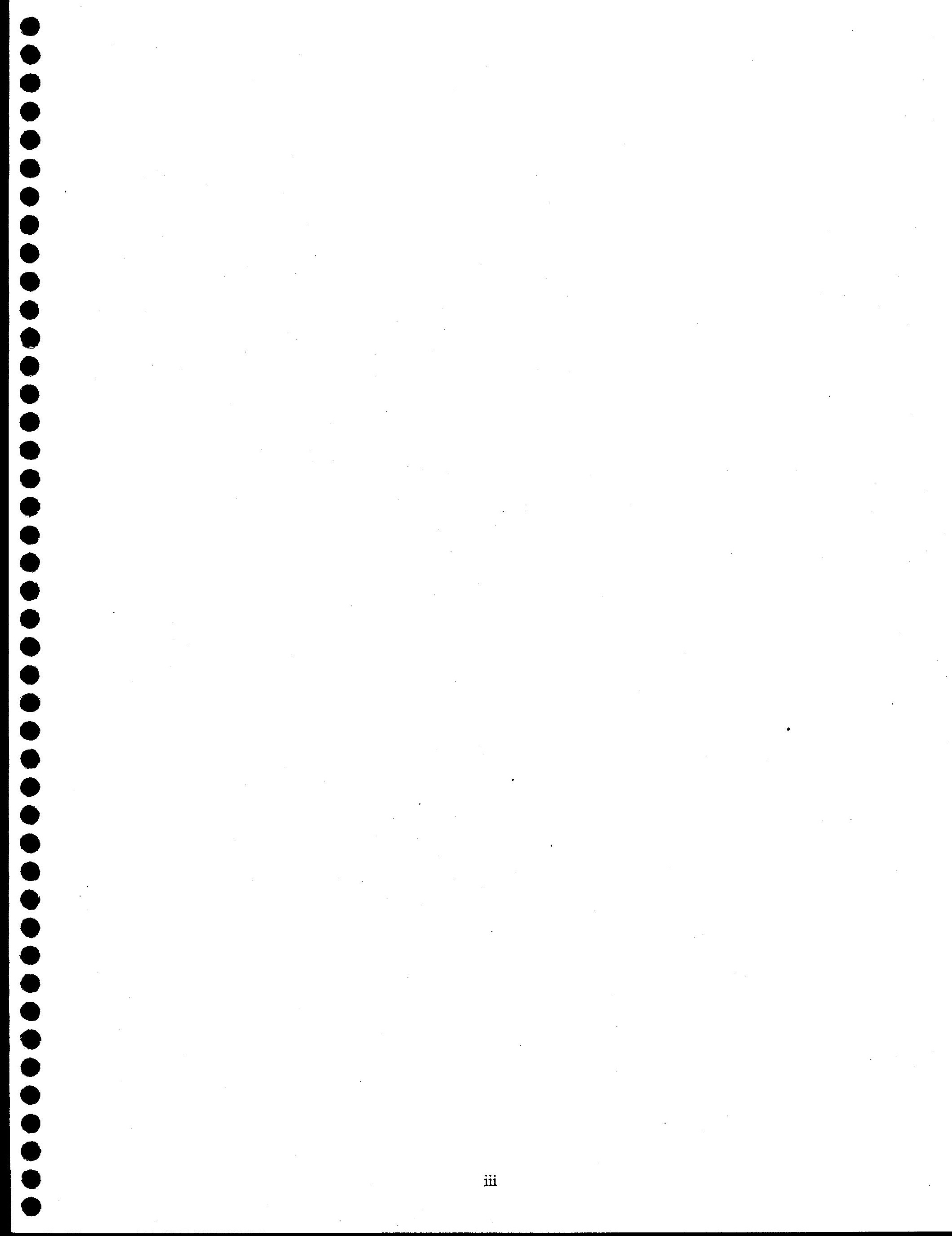




\section{ACKNOWLEDGMENTS}

We extend our thanks to Colin Boardman, Rebecca Robbins, and Tim Milner of BNFL Inc., for their assistance and support. Thanks also to Neil Smart, Robin Taylor, and Mike Carrott of BNFL plc., for their input and discussions. We would also like to acknowledge Chien Wai at the University of Idaho and Sue Clark at Washington State University for their assistance.

Acknowledgments are also given to J.W. Rogers and the excellent staff of the Radiation Measurements Laboratory (RML) at the INEEL TRA. We appreciate their dedication to producing the highest quality data while having a keen awareness of timing and programmatic scheduling. We also appreciate their willingness to go out of their way to provide expert assistance with a "can do" attitude.

We would also like to acknowledge John Eisenmenger and Brian Harris of the RML for their work to obtain the alpha spectrometry data.

Finally, our thanks to Duane Siemer for his work on characterizing the soil samples and to Ryan McMurtrey and the rest of the Supercritical Fluid Team at the INEEL for their assistance and support. 


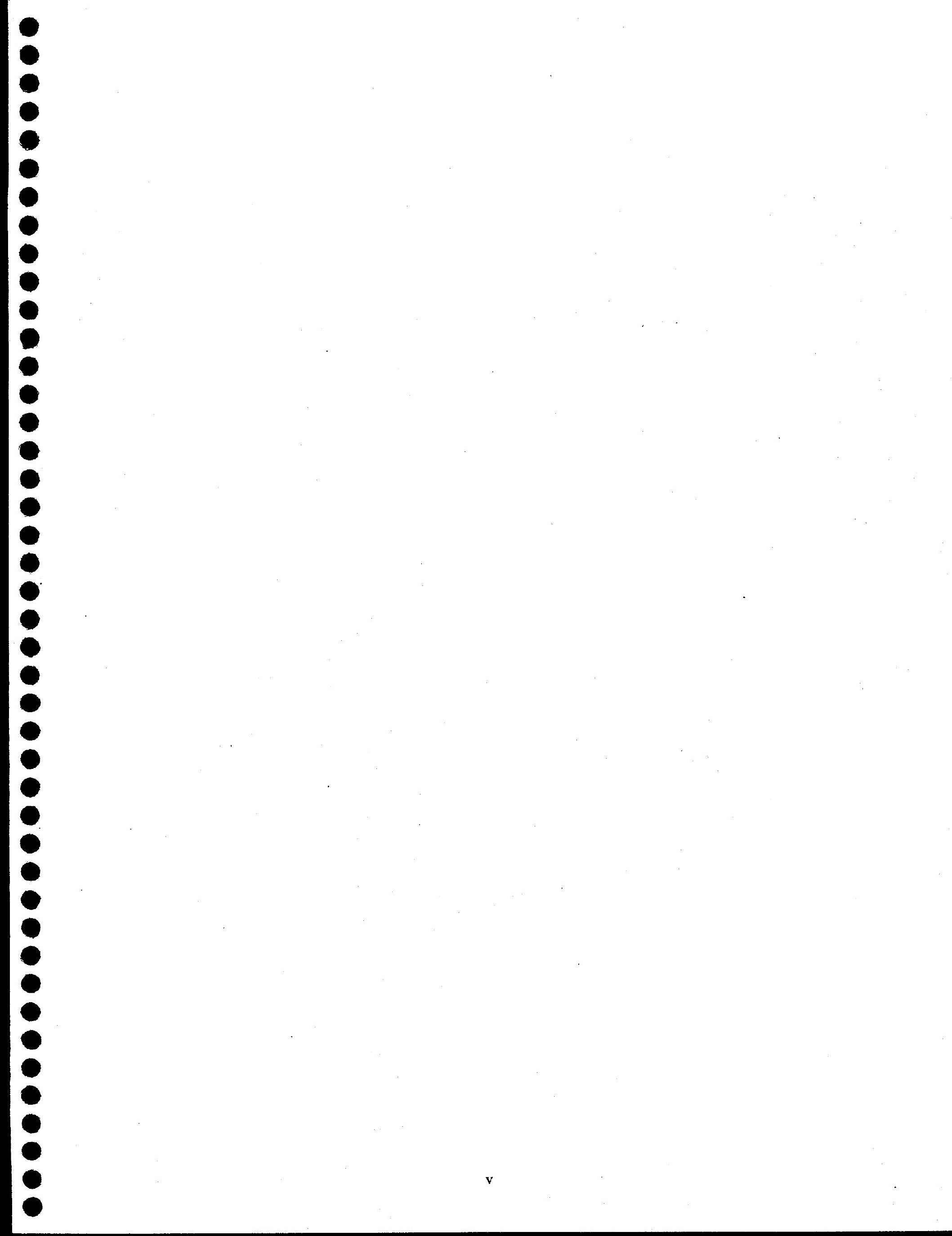




\section{CONTENTS}

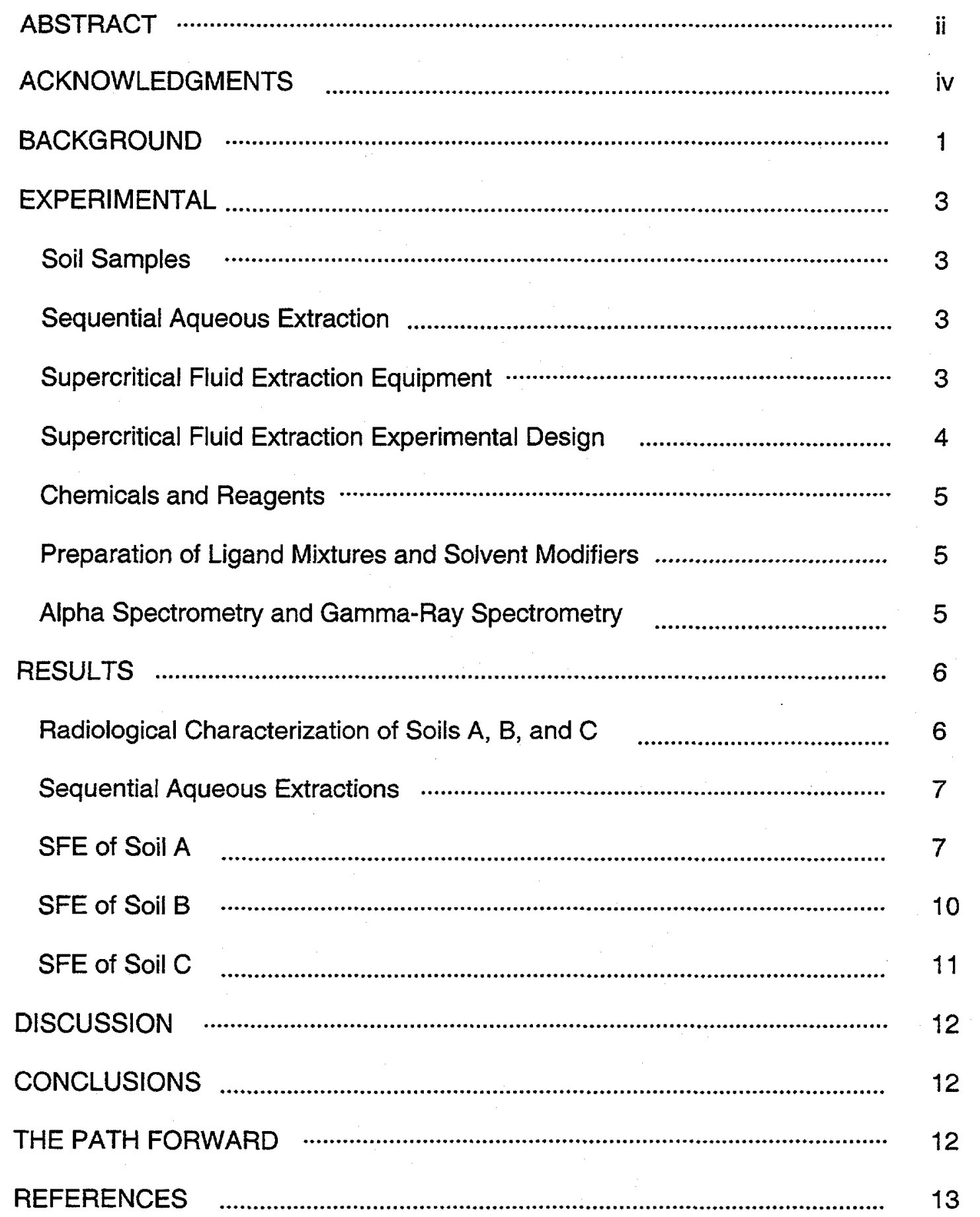

\section{FIGURES}

Figure 1. Process Schematic for SFE Set-Up 


\section{TABLES}

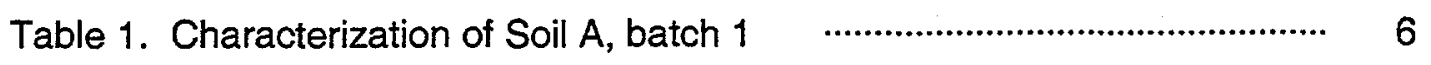

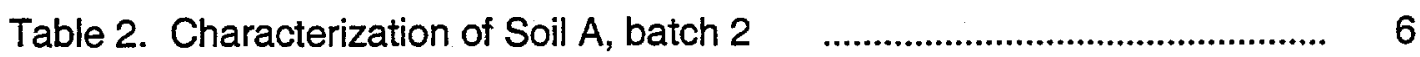

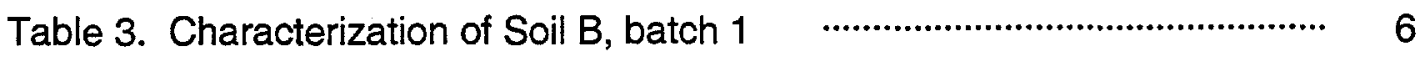

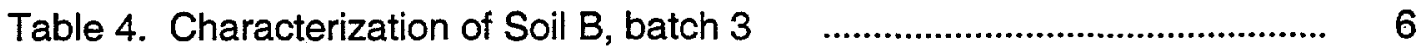

Table 5. Characterization of Soil C, batch 1

Table 6. Sequential Aqueous Extraction …..................................................... 7

Table 7. LA-SFE Results for Soil A

Table 8. LA-SFE Results for Soil B $\quad$............................................................ 10

Table 9. LA-SFE Results for Soil C 


\section{Extraction of Plutonium From Spiked INEEL Soil Samples Using the Ligand-Assisted Supercritical Fluid Extraction (LA-SFE) Technique}

\section{BACKGROUND}

In November of 1989 the Environmental Protection Agency (EPA) added the Idaho National Engineering and Environmental Laboratory (INEEL) to the National Priorities List (NPL) under the Comprehensive Environmental Response, Compensation and Liability Act (CERCLA). The Federal Facility Agreement and Consent Order (FFA/CO) was negotiated and signed by the DOE-ID, the EPA, and the State of Idatho Department of Health and Welfare late in 1991 to implement the remediation of the INEEL under CERCLA. The INEEL was divided into 10 Waste Area Groups (WAGs), of which the Radioactive Waste Management Complex (RWMC) was designated as WAG 7. ${ }^{1}$

The RWMC is a 174 acre area located in the southwest corner of the INEEL. The RWMC is subdivided into 3 separate areas based on function; the Subsurface Disposal Area (SDA), the Transuranic Storage Area (TSA), and the Administrative Area. The SDA at the RWMC is a 96 acre area located at the west section of the Complex and is dedicated to permanent shallow-land disposal of solid, low-level waste. The SDA contains 20 pits, 58 trenches, 15 rows of soil vaults, and 1 aboveground pad. Transuranic (TRU) and low-level waste (LLW) was disposed at the SDA from 1952 to 1984; although, sub-surface disposal of material was stopped after 1970 and stored aboveground on asphalt pads. Various reports indicate that the total quantities of waste at the SDA includes approximately 4 million cubic feet of LLW and approximately 2 million cubic feet of TRU waste for a total volume of approximately 6 million to 7 million cubic feet assuming an average 18 foot depth. Because many of the original waste containers are thought to have degenerated, it has been estimated that the contaminated soils above, in, under, and around the pits, trenches and vaults at the SDA could potentially contribute as much as an additional 11 million cubic feet of contaminated soils to the overall waste stream. ${ }^{2}$ However, a new estimate is currently being prepared by DOE-ID and conveys a much smaller figure. Thus, the two primary waste forms found at the SDA are porous soils and solid wastes and a conservative estimate places the total volume of material at approximately 18 million cubic feet pending new and more accurate information. From various inventories taken at the time of emplacement, it was determined that the radioactive materials amounted to approximately 9.5 million $\mathrm{Ci}$ and included more than 1 million grams of plutonium and more than 270 million grams of uranium and their respective daughter products. Additionally, the solid wastes and soils are expected to contain a variety of organic compounds, inorganic salts, and heavy metals. ${ }^{3}$

Currently the Baseline Risk Assessment and a number of Treatability Studies are underway and will provide information for the comprehensive Remedial Investigation/Feasibility Study (RI/FS) Report due in 2002. The Baseline Risk Assessment will determine whether the site poses an unacceptable risk and will detail specific contaminants, exposure pathways and consequences to human health and the environment. It is anticipation either in situ and/or ex situ treatment will be required and a number of technologies will be tested in Treatability Study Trials using actual soil and waste samples. The results of the Baseline Risk Assessment and the technology Treatability Studies will be evaluated in the RI/FS Report. The remediation plan recommended in the RI/FS, subject to public comment, will be acted upon by signing a Record of Decision in early 2003.

All currently available soil remediation techniques have some shortcomings e.g., high volume of secondary waste, destructive to the soil matrix, etc. This led BNFL to investigate ligand-assisted supercritical fluid extraction (LA-SFE) as a clean technology for soil remediation. The origin of the LASFE technique can be traced directly back to the DOE and the University of Idaho.

In 1991 Dr. Chien Wai at the University of Idaho (U of I) received funding from the U.S. DOE Office of Technology Development, Innovative Technology Program through a proposal submitted to the DOEIdaho Operations Office. The funding received from the DOE provided for the development of a 
technique wherein a metal chelating agent is dissolved into a supercritical fluid and that solvent is then used to selectively extract metals from solid surfaces. 4,5 Thus, the power of molecular recognition science was brought to bear in an inherently waste minimizing solvent system. Since his initial discovery Dr. Wai has published more than 125 papers on the technique and more than 500 different technical papers can now be found on the subject in the open scientific literature. In 1992 researchers at the INEEL, in collaboration with Dr. Wai at the $U$ of I, began further development and demonstration of the technique by conducting Treatability Studies on various radioactive contaminated waste forms at the INEEL. Using the ligand-assisted supercritical fluid extraction technique INEEL researchers successfully removed cobalt- 60 from contaminated lead shot. The technique selectively removed the cobalt and left the lead behind; producing clean lead and a low volume secondary waste which was free of lead but contained the radionuclide. The lead shot was cleaned to the point of being able to be returned to service as shielding material. ${ }^{6}$ These successes led both the INEEL and the $U$ of $I$ to realize that the LA-SFE technique could be highly useful for selective and efficient removal of radionuclides from a variety of matrices.

Also in 1991 British Nuclear Fuels plc (BNFL) initiated a study of metal solubility in supercritical carbon dioxide at the University of Leeds (U.K.). In 1992 BNFL continued collaboration with the University of Leeds (U.K.) and initiated an additional collaboration with the V.G. Khlopin Radium Institute in St. Petersburg, Russia. In 1993/1994 BNFL established a research agreement and license for existing/future $U$ of I patents and began a research collaboration with Chien Wai in the area of supercritical fluid extraction. Neil Smart from BNFL was assigned as an Assistant Professor at the $U$ of $I$ to coordinate the collaboration. ${ }^{7}$ In 1996 a joint collaboration between the $U$ of $I$ and the INEEL was formed through the INEELMIT University Research Consortium (URC) to jointly work on developing supercritical fluid extraction applications for removal of metals/radionuclides from environmental matrices (soil/water). BNFL participated in the collaboration as the industrial partner. That collaboration led to joint publications and presentations in the area of supercritical fluid extractions and also led to additional patents and publications by the INEEL, the U of I and BNFL. ${ }^{8}$ In 1998/1999, BNFL funded Sue Clark at Washington State University to initially investigate extraction of plutonium from soil samples obtained through the National Institute of Standards and Technology (NIST). A follow-up program was established at the INEEL using higher concentrations of plutonium spiked into RWMC soil samples.

Apart from these developments in nuclear applications, the use of SFE to remove organic contaminants from soil, at scale, is well known. In 1997/1998, BNFL became interested in such a project managed by MK at Conroe, Texas where SFE was successfully demonstrated at an EPA Superfund Site. SFE technology was applied to extract toxic organics from soil at rates of $150+$ tons/day. This large scale application gave confidence the process could be engineered at scale and could remove organic contaminants from soil.

Research staff at the INEEL have been engaged in an ongoing effort sponsored by BNFL Inc. and BNFL plc, to develop supercritical fluid extraction technology for use in cleaning contaminated soils. The process developed thus far incorporates supercritical carbon dioxide, and various compositions of cosolvents and complexing agents. The work involves multiple phases that will take the technology from "Proof-of-Principle" through Treatability Trials, scale-up and optimization, to full-scale implementation at one or more DOE sites. The initial Proof-of-Principle work had a three-fold purpose. The tests were designed to provide data: 1) to demonstrate the capability of supercritical carbon dioxide in delivering complexing agents into complex soil matrices, 2) for determining the binding strength and mobility of the resultant complexes, and 3 ) for evaluating the removal of radioactive compounds from soils.

Removal of $80 \%$ of the plutonium in spiked soil samples in the initial studies was observed under the extraction conditions without any optimization. This degree of extraction, along with other important information gathered, was sufficient to consider the Proof-of-Principle phase complete and successful. Cost, scope, and schedule for the continued development of this particular SFE technology are currently under negotiation. The next phase will be a Treatability Study on a small scale, and will attempt to optimize the chemical composition of the extracting medium and the process parameters. Future work 
will also incorporate engineering principles for equipment and process design that will facilitate scale-up of the technology while maintaining process efficiency.

This document reports the results from the initial Proof-of-Principle studies of ligand-assisted supercritical fluid extraction of plutonium from spiked RWMC soils. The BNFL proprietary information has been purposely removed from this document as per contractual agreement between LMITCO, DOE-ID, and BNFL.

\section{EXPERIMENTAL}

Soil Samples. $1 \mathrm{Kg}$ of RWMC lake bed soil was obtained from the INEEL RWMC area. The soil was obtained from the spreading area (B) outside of the RWMC boundary and is comprised of a silt-clay surficial material obtained from within the 1 foot to 10 foot depth. An initial gross screen of the soil took place on-site to remove bulk organic and inorganic materials (sagebrush, rocks, etc.). A final screen was done where the soil was sifted to 50 mesh prior to further use and radiological characterization. The soil was radiologically characterized prior to further experimental use. After radiological characterization three different $100 \mathrm{~g}$ fractions of the RWMC soil were split out from the main batch and designated as soils $A$, $\mathrm{B}$, and $\mathrm{C}$. The following soil preparations were made as per the specifications of the customer. ${ }^{9}$

The $100 \mathrm{~g}$ fraction of soil A was placed in a beaker and enough deionized water was added to make an easily stirred soil slurry. The soil slurry was then spiked with $500 \mathrm{nCi} / \mathrm{g}$ plutonium nitrate in $8 \mathrm{M}$ nitric acid. The spike was made using a total of $1.9 \mathrm{ml}$ of liquid dispensed in 100 microliter aliquots followed by stirring for 1 minute between aliquots. The soil was dried at $65^{\circ} \mathrm{C}$ for 4 days. $10 \mathrm{~g}$ samples were then obtained and assayed using gamma spectrometry.

The $100 \mathrm{~g}$ fraction of soil $\mathrm{B}$ was prepared and spiked with $500 \mathrm{nCi} / \mathrm{g}$ plutonium in the same manner as soil A except the $32 \mathrm{ml}$ of deionized water added to make the soil slurry contained $1000 \mathrm{ppm}$ nitrate in the form of dissolved sodium nitrate salt. Additionally, the soil was heated to $500{ }^{\circ} \mathrm{C}$ for 2 hours after the initial drying step. $10 \mathrm{~g}$ samples were then obtained and assayed using gamma spectrometry.

The $100 \mathrm{~g}$ fraction of soil $\mathrm{C}$ was placed in a beaker and a soil slurry was prepared using a $250 \mathrm{ml}$ solution containing $65 \mathrm{mg} \mathrm{Fe}_{2}\left(\mathrm{SO}_{4}\right)_{3}, 10 \mathrm{mg} \mathrm{Na} \mathrm{CO}_{3}$, and $10 \mathrm{mg} \mathrm{Na}_{3} \mathrm{PO}_{4}$. The slurry was $\mathrm{pH}$ adjusted to 11.0 with sodium hydroxide prior to being spiked with $1000 \mathrm{nCi} / g$ plutonium nitrate in $8 \mathrm{M}$ nitric acid. The soil was then dried in the same manner as described in the preparation of soil $A$ above. $10 \mathrm{~g}$ samples were obtained and assayed using gamma spectrometry.

Sequential Aqueous Extraction. As a means to characterize the spiked soil samples a grading technique was used to determine to which soil fraction, and how strongly, the actinides were bound. The grading technique followed a published procedure. Samples were obtained from each soil preparation and were subjected to the sequential aqueous extraction procedure of Tessier et al. ${ }^{10}$ Briefly, a soil sample is subjected to different chemical reagents in a given sequence. Each reagent is designed to remove metal associated with that particular soil fraction (e.g., those easily removed from ion exchange sites, or those removed as a result of a change in $\mathrm{pH}$, etc.). If after all reagents are used and no metal has come out, then the remaining metal is said to have partitioned into the residual fraction.

Supercritical Fluid Extraction Equipment. A general process diagram of the extraction system is found in Figure 1. The extraction system employed was constructed with the intent to economize system cost yet maximize the number of samples which could be run while varying multiple extraction parameters. The system uses a rudimentary plug-flow design which in no way represents an optimized system or the most efficient engineering design which can be employed. The SFE system consisted of two ISCO model $500 \mathrm{D}$ precision metering pumps and a single ISCO model $260 \mathrm{D}$ precision metering pump. The three pumps were controlled by a single ISCO series D pump controller (ISCO Inc., Lincoln, NE.). The $500 \mathrm{ml}$ pumps were equipped with cooling jackets and were used for solvent delivery. The $260 \mathrm{ml}$ pump was used for delivery of the liquid ligand mixture. The pressurized solvent was pumped into a pre-heated 
zone and brought to temperature. The pressurized ligand was also pumped to the pre-heated zone and brought to temperature. The solvent and ligand were then mixed together after the pre-heat zone and passed through a short, heated mixing zone. The solvent containing the ligand was then passed over the soil sample which was contained in a heated, 15 inch long piece of $1 / 2$ inch diameter high-pressure tubing which served as the extraction vessel. The downstream components were also heated and were composed of an Autoclave Engineers (Autoclave Engineers Group, Erie, PA.) in-line filter (10 micron and 5 micron sintered metal frits), an Autoclave Engineers 3-way valve, an Autoclave Engineers

Micrometering Valve which was used as a back-pressure regulator and process flow controller, and a 250 $\mathrm{ml}$ side-arm vacuum flask which served as the collection vessel. The solvent pumps were operated in constant pressure mode and the ligand delivery pump was operated in constant flow mode. The total system flow was regulated by the micrometering valve. The system flow was kept at $3.5 \mathrm{ml} / \mathrm{min} \pm 0.2 \mathrm{ml}$ during all extractions and increased or decreased as needed during temperature equilibration and system flush out.

The pre-heat zone temperature, extraction vessel temperature, and downstream temperature was controlled using heat tapes, Omega type $K$ thermocouples, and Omega CN76000 1/16 DIN Auto-Tune process controllers (Omega Engineering Inc., Stamford, CT.). System pressure was controlled using the metering pumps and the micrometering valve and monitored via the pressure transducers on the pumps and a single Omega model PX605 pressure transducer located downstream of the pre-heater and upstream of the extraction vessel. The thermocouples were calibrated against NIST traceable temperature calibration standards and all were found to be within the manufacturer's accepted error range. The pressure transducers on each of the ISCO pumps and the Omega model PX605 transducer were calibrated using a calibrated Heise model CC pressure gauge (Dresser Industries, Newton, CT.).

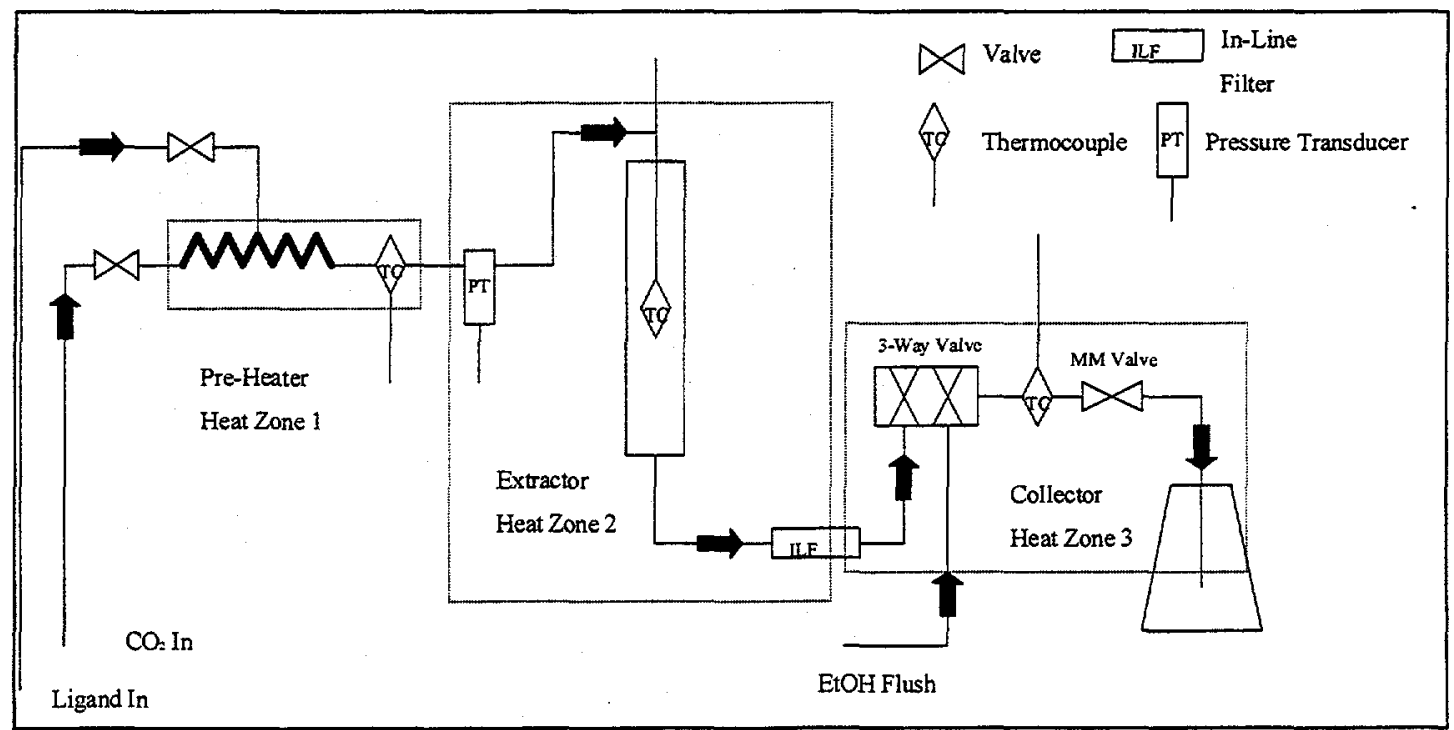

Figure 1 Process Schematic for SFE Set-Up

Supercritical Fluid Extraction Experimental Design. Soil was placed into the extraction vessel and the ends were plugged with glass wool and the fittings installed. The extraction vessel was installed in the system, solvent flow was started, and the power was turned $O N$ to the heat tapes. The system was allowed to temperature and pressure equilibrate for 30 to 45 minutes with solvent flow. After the equilibration period the ligand pump was started and the extraction experiment began. The extractions were run for $\mathbf{4 5}$ minutes at which time the ligand pump was turned OFF. The system was allowed to flush for 10 to 15 minutes with solvent flow then depressurized and cooled. The 3-way valve was used to isolate the extraction vessel and upstream components from the downstream components and ethanol was pumped into the downstream system for 3 to 5 minutes at a rate of $5 \mathrm{ml} / \mathrm{min}$ to flush the downstream system. Excess ethanol was pushed from the downstream system by allowing a small amount of pressurized solvent to flow from the upstream system through to the downstream system. Each 
extraction was run in duplicate or triplicate to authenticate the results which are then reported as an average.

Chemicals and Reagents. Compressed gas used as the supercritical fluid solvent was obtained in $60 \mathrm{lb}$ quantities from U.S. Welding (Pocatello, ID.) and was listed as $99.8 \%$ pure from the supplier. Ligands and ethyl alcohol 100\% were obtained from Aldrich (Aidrich Chemical Co., St. Louis, MO.). Sodium nitrate, sodium phosphate, sodium carbonate, sodium hydroxide, ammonium hydroxide, aluminum nitrate, nitric acid, ascorbic acid, sodium nitrite, hydrochloric acid, lithium meta-borate, and hydrofluoric acid were also obtained from Aldrich. Ferric sulfate was obtained from Mallinckrodt (Mallinckrodt Baker Inc., Phillipsburg, NJ.).

Preparation of Ligand Mixtures and Solvent Modifiers. Proprietary Information.

\begin{abstract}
Alpha Spectrometry and Gamma-Ray Spectrometry. Soils containing low levels of plutonium were analyzed by alpha spectrometry. Aliquots of soil were fused using lithium meta-borate at $1020^{\circ} \mathrm{C}$. The resulting cake was dissolved in dilute nitric acid. The dissolution was made basic with ammonium hydroxide and the resulting precipitate, containing the plutonium, was collected by centrifugation. The precipitate was dissolved in $2.5 \mathrm{M}$ nitric acid and aluminum nitrate was added as a salting-out agent. The solution was then treated with ascorbic acid and sodium nitrite to ensure that plutonium was in the Pu (IV) valence state. The solution was loaded onto a commercially available TEVA column (EIChroM Industries, Evanston, IL.), which absorbs Pu (IV). Following the separation, Pu (IV) was eluted with $0.5 \mathrm{M}$ hydrochloric acid. Neodymium carrier was added to the purified plutonium solution, which was then treated with hydrofluoric acid to precipitate the neodymium. The precipitate, carrying the plutonium, was filtered and the filters were mounted on planchetts for alpha spectrometry. Alpha counting was accomplished using surface barrier detectors and a multi-channel analyzer.
\end{abstract}

Samples having above about $30 \mathrm{nCi} / \mathrm{g}$ plutonium were radioactive enough to be counted by gamma-ray spectrometry. The gamma-ray spectrometry measurements used to quantify the radionuclides of the soil and liquid samples were made using intrinsic germanium detector based gamma-ray spectrometer systems. The systems were calibrated for energy and efficiency. The gamma-ray spectra from the measurements of samples were analyzed using the Radiation Measurements Laboratory (RML) VAXGAP (VAX-DEC6000-310) (GAP-Gamma Analysis Program). The soil sample geometry was $10 \mathrm{~cm}^{3}(\sim 12 \mathrm{~g})$ in a plastic vial $\left(2.5 \mathrm{~cm}\right.$ diameter and $2.5 \mathrm{~cm}$ high). The liquid sample geometry was $60 \mathrm{~cm}^{3}(\sim 60 \mathrm{ml})$ in a plastic bottle ( $3.8 \mathrm{~cm}$ diameter and $6.4 \mathrm{~cm}$ high). The efficiency calibrations for the sample geometries were established by spiking the matrix materials (soil and liquid) with known amounts of radioactive source materials containing gamma emitting radionuclides over the energy range from $60 \mathrm{keV}$ to 3.0 $\mathrm{MeV}$. The efficiency calibration curves were established to an estimated uncertainty of $\pm 2.5 \%$ at the $68 \%$ confidence level. The energy calibrations were established with the thorium-228 daughter gammarays at $238.6,583.2,860.5,1620.7$ and $2614.5 \mathrm{keV}$ using a quadratic fit of the energy versus channel to an estimated uncertainty if $\pm .03 \mathrm{keV}$ over this energy range. The intrinsic germanium detectors were about $12 \%$ relative efficiency with energy resolution of about $1.8 \mathrm{keV}$ at $1.33 \mathrm{MeV}$ in shielded integral cryostats (CANBERRA and PGT). The detector bias supplies and linear amplifiers (ORTEC) along with the 8192 channel multi-channel data acquisition interface module and analog to digital converters (CANBERRA) were modern state of the art electronic modules.

The gamma-ray spectra were analyzed using the RML VAXGAP data acquisition and analysis programs. Each gamma-ray spectrum measured had the identification, energy and efficiency calibration, and analysis control parameters attached when it was analyzed and stored. The analysis programs locate the photopeaks by zero area correlation methods where the sensitivity has been optimized. The peak areas are determined by Gaussian-function least-squares fitting and step function background subtraction. The photopeak energy location is determined by the peak analysis and the energy calibration functions. The possible radionuclide identifications are then determined by comparing the observed photopeak energies with the known photon energies of the radionuclides residing in the decay data library and based on the acceptance criteria associated with the energy calibration. The radionuclide activities are then calculated based on the efficiency, emission probability and half-life. Decay corrections are made based on the 
reference time and date and the duration of the counting period. If specified, interference corrections between photopeaks of different radionuclides may be performed. Where multiple photopeaks are associated with a radionuclide, the activity of each peak is determined and a weighted average of all peaks is computed based on the intensity code and uncertainty in the peak areas. For these measurements the only radionuclides of interest were Pu-239 and Am-241. The Am-241 was identified and quantified by the $59.54 \mathrm{keV}$ photopeak and the Pu-239 was identified and quantified by the 129.3, $144.2,203.5,332.9,345.0,375.0$ and $413.7 \mathrm{keV}$ photopeaks where the $129.3 \mathrm{keV}$ peak is the highest intensity area. These measurement conditions typically produced results with precision ranging from 2 to 5 percent at the 68 percent confidence level.

Each spectrum measurement and analysis was inspected and verified for correctness and accuracy. Photopeak results were inspected to assure proper correlation and combination. Routine energy and efficiency calibration checks were made on the spectrometry systems and were found to be normal and stable. Recounts of some samples showed the reproducibility to be consistent with the estimated uncertainties of the individual measurements. These inspections, checks and comparisons were performed by a trained and experienced gamma-ray spectrometrist.

\section{RESULTS}

Radiological Characterization of Soils A, B, and C. Soil A, batch 1 was prepared, spiked and radiologically characterized. The plutonium and americium levels are shown in Table 1. The mean activity value was used in estimating mass balances. The analysis results demonstrate $\mathrm{a} \pm 27 \mathrm{nCi} / \mathrm{g}(5.8 \%)$ variability between samples. The variation can possibly be attributed to multiple factors including inhomogeneity and errors associated with counting; however, the gamma spectrometry counting statistics across all soil $A, B$, and C samples were typically very good for both Pu-239 and Am-241 showing less than $1 \%$ relative standard error. Soil A, batch 2 characterization results are found in Table 2. Soil B, batch 1 was prepared, spiked and the radiological characterization results are found in Table 3 . Soil B, batch 3 characterization results are found in Table 4. Finally, soil $\mathrm{C}$, batch 1 was prepared, spiked and the radiological characterization results are found in Table 5 .

Table 2 Characterization of Soil A, batch 2

\begin{tabular}{|lcc|}
\hline Trial \# & nCi/g Pu-239 & nCi/g Am-241 \\
\hline Trial 1 & 468.4 & 2.52 \\
Trial 2 & 505.6 & 2.50 \\
\hline Mean & $487+/-26$ & $2.51+/-0.01$ \\
\hline
\end{tabular}

Table 4 Characterization of Soil B, batch 3

\begin{tabular}{|lcc|}
\hline Trial \# & $\mathrm{nCi} / \mathrm{g}$ Pu-239 & $\mathrm{nCi} / \mathrm{g}$ Am-241 \\
\hline Trial 1 & 482 & 2.62 \\
Trial 2 & 452 & 2.36 \\
\hline Mean & $467+/-21$ & $2.49+/-0.18$ \\
\hline
\end{tabular}

Table 1 Characterization of Soil A, batch 1

\begin{tabular}{|lcc|}
\hline Trial \# & nCi/g Pu-239 & nCi/g Am-241 \\
\hline Trial 1 & 434.2 & 2.27 \\
Trial 2 & 464.4 & 2.39 \\
Trial 3 & 500.7 & 2.65 \\
Trial 4 & 468.5 & 2.51 \\
\hline Mean & $467+/-27$ & $2.46+1-0.16$ \\
\hline
\end{tabular}

\begin{tabular}{|c|c|c|}
\hline Trial \# & nCi/g Pu-239 & $\mathrm{nCi} / \mathrm{g}$ Am-241 \\
\hline $\begin{array}{l}\text { Trial } 1 \\
\text { Trial } 2 \\
\text { Trial } 3\end{array}$ & $\begin{array}{l}528.2 \\
442.5 \\
424.0\end{array}$ & $\begin{array}{l}2.85 \\
2.32 \\
2.25\end{array}$ \\
\hline Uean & $465+l-56$ & $2.47+1-0.32$ \\
\hline
\end{tabular}

Table 5 Characterization of Soil C, batch 1

\begin{tabular}{|lcc|}
\hline Trial \# & $\mathrm{nCi} / \mathrm{g} \mathrm{Pu}-239$ & $\mathrm{nCi} / \mathrm{g} \mathrm{Am}-241$ \\
\hline Trial 1 & 962.9 & 5.08 \\
Trial 2 & 1025.4 & 5.53 \\
\hline Mean & $994+/-44$ & $5.30+/-0.32$ \\
\hline
\end{tabular}


Sequential Aqueous Extraction. Soils $A, B$, and $C$ were subjected to the aqueous extraction procedure. The results are found in Table 6.

Table 6 Sequential Aqueous Extraction

\begin{tabular}{|ccc|}
\hline & SOIL A & \% Am Recovered \\
\hline Soil Fraction & \% Pu Recovered & 0 \\
Ion Exchangeable & 0 & 0 \\
Carbonate & 0 & 73 \\
Iron/Manganese & 0 & 0 \\
Organic & 0 & \% Am Recovered \\
\hline Soil Fraction & SOlL B & 0 \\
\hline Ion Exchangeable & \% Pu Recovered & 0 \\
Carbonate & 0 & 80 \\
Iron/Manganese & 0 & 10 \\
Organic & 0 & \\
Soil Fraction & 0 & Am Recovered \\
\hline Ion Exchangeable & SOIL C & 0 \\
Carbonate & Pu Recovered & 0.5 \\
Iron/Manganese & 0 & 77 \\
Organic & 0 & 22 \\
\hline
\end{tabular}

SFE of Soil A. Ligand-assisted supercritical fluid extractions were conducted on approximately $10 \mathrm{gm}$ per sample of soil A. The extraction radioanalytical results for the post-extracted soil and collected liquid extract (ligand) are found in Table 7. The value for $\% E$ is the quotient of the activity measured in the ligand (a measurement of the activity actually removed from the soil in the column) over (divided by) the known amount of plutonium loaded into the column. This activity in the column is determined by multiplying the mean specific activity value for the soil by the mass loaded. A mass balance for the experiment is determined by comparing the total activity of plutonium in the pre-, and post-extraction soils with the amount of plutonium recovered in the ligand. An error of less than $20 \%$ was considered acceptable against the mass balance.

Table 7 LA-SFE Results for Soil A

Conditions: Proprietary Information

\section{Initial Extraction}

Radiological Activity (nCi)

Extraction \#

1

2

3

\begin{tabular}{|c|c|c|c|c|c|c|c|c|c|}
\hline \multicolumn{8}{|c|}{ Radiological Activity (nCi) } & \multirow{2}{*}{\multicolumn{2}{|c|}{ \% Extracted }} \\
\hline \multicolumn{2}{|c|}{ Pre-Soil } & \multicolumn{2}{|c|}{ Post-Soil } & \multicolumn{2}{|c|}{ Change } & \multicolumn{2}{|c|}{ Ligand } & & \\
\hline $\mathrm{Pu}$ & Am & $\mathrm{Pu}$ & Am & $\mathrm{Pu}$ & $\mathrm{Am}$ & $\mathrm{Pu}$ & $\mathrm{Am}$ & $\mathrm{Pu}$ & $\mathrm{Am}$ \\
\hline 6781 & 35.7 & 4830 & $\overline{19.5}$ & 1951 & $\overline{16.3}$ & 1023 & 10.6 & 15 & 30 \\
\hline 4643 & 24.5 & 3810 & 14.8 & 833 & 9.70 & 968 & 9.25 & 21 & 38 \\
\hline \multirow[t]{4}{*}{5198} & 27.4 & 4791 & 19.9 & 407 & 7.50 & 718 & 8.00 & 14 & 29 \\
\hline & & & & & & & & \multicolumn{2}{|c|}{ Averages } \\
\hline & & & & & & & & $\mathrm{Pu}$ & $\mathrm{Am}$ \\
\hline & & & & & & & & 17 & 32 \\
\hline
\end{tabular}


Table 7 Continued

\section{Condition Change \#1 Increase Ligand Concentration}

Conditions: Proprietary Information

\begin{tabular}{|c|c|c|c|c|c|c|c|c|c|c|}
\hline \multirow[b]{3}{*}{ Extraction \# } & \multicolumn{8}{|c|}{ Radiological Activity (nCi) } & & \\
\hline & \multicolumn{2}{|c|}{ Pre-Soil } & \multicolumn{2}{|c|}{ Post-Soil } & \multicolumn{2}{|c|}{ Change } & \multicolumn{2}{|c|}{ Ligand } & \multicolumn{2}{|c|}{$\%$ Extracted } \\
\hline & $\mathrm{Pu}$ & $\mathrm{Am}$ & $\mathrm{Pu}$ & Am & $\mathrm{Pu}$ & Am & $\mathrm{Pu}$ & $\mathrm{Am}$ & Pu & $\mathrm{Am}$ \\
\hline 1 & 5151 & 27.1 & 1614 & 4.97 & 3537 & 22.1 & 3300 & 22.0 & 64 & 81 \\
\hline $2^{\star \star}$ batch 2 & 4460 & 23.0 & 1408 & 4.00 & 3052 & 19.0 & 3270 & 21.0 & 73 & 91 \\
\hline \multirow[t]{3}{*}{$3^{\star \star}$ batch 2} & 4565 & 23.5 & 1342 & 4.60 & 3223 & 18.9 & 3215 & 21.7 & 70 & 92 \\
\hline & & & & & & & & & \multicolumn{2}{|c|}{ Averages } \\
\hline & & & & & & & & & 69 & 88 \\
\hline
\end{tabular}

Conditions: Proprietary Information

\section{Condition Change \#2 Pre-Treat Soil}

\begin{tabular}{|c|c|c|c|c|c|c|c|c|c|c|}
\hline \multirow[b]{3}{*}{ Extraction \# } & \multicolumn{8}{|c|}{ Radiological Activity ( $\mathrm{nCi}$ ) } & & \\
\hline & \multicolumn{2}{|c|}{ Pre-Soil } & \multicolumn{2}{|c|}{ Post-Soil } & \multicolumn{2}{|c|}{ Change } & \multicolumn{2}{|c|}{ Ligand } & \multicolumn{2}{|c|}{$\%$ Extracted } \\
\hline & $\mathrm{Pu}$ & Am & $\mathrm{Pu}$ & Am & $\mathrm{Pu}$ & $\mathrm{Am}$ & $\mathrm{Pu}$ & $\mathrm{Am}$ & $\mathrm{Pu}$ & $\mathrm{Am}$ \\
\hline 1 & 4484 & 23.6 & 3636 & 11.7 & 848 & 12.0 & 1416 & 13.2 & 32 & 56 \\
\hline 2 & 3653 & 19.2 & 2993 & 10.3 & 660 & 8.90 & 1112 & 10.4 & 30 & 54 \\
\hline \multirow[t]{3}{*}{3} & 4227 & 22.2 & 3305 & 12.4 & 922 & 9.84 & 1153 & 11.8 & 27 & 53 \\
\hline & & & & & & & & & \multicolumn{2}{|c|}{$\begin{array}{l}\text { Averages } \\
\text { Pu } \quad \text { Am }\end{array}$} \\
\hline & & & & & & & & & 30 & 54 \\
\hline \multicolumn{11}{|c|}{ Condition Change \#3 Addition of Solvent Modifier \#1 } \\
\hline & \multicolumn{8}{|c|}{ Radiological Activity ( $\mathrm{nCi}$ ) } & & \\
\hline & \multicolumn{2}{|c|}{ Pre-Soil } & \multicolumn{2}{|c|}{ Post-Soil } & \multicolumn{2}{|c|}{ Change } & \multicolumn{2}{|c|}{ Ligand } & \multicolumn{2}{|c|}{$\%$ Extracted } \\
\hline \multirow{7}{*}{$\begin{array}{c}\text { Extraction \# } \\
1 \\
2^{* \star} \text { batch } 2 \\
3^{\star \star} \text { batch } 2\end{array}$} & $\mathrm{Pu}$ & Am & $\mathrm{Pu}$ & Am & $\mathrm{Pu}$ & Am & $\mathrm{Pu}$ & Am & $\mathrm{Pu}$ & Am \\
\hline & 4895 & 25.8 & 2729 & 10.8 & 2166 & 15.0 & 2036 & 16.3 & 42 & 63 \\
\hline & 5104 & 26.3 & 2684 & 9.85 & 2420 & 16.5 & 2047 & 15.2 & 40 & 58 \\
\hline & 5289 & 27.3 & 3343 & 11.7 & 1946 & 15.6 & 2842 & 15.4 & 54 & 56 \\
\hline & & & & & & & & & \multicolumn{2}{|c|}{ Averages } \\
\hline & & & & & & & & & & $\mathrm{Am}$ \\
\hline & & & & & & & & & 45 & 59 \\
\hline \multicolumn{11}{|c|}{$\begin{array}{c}\text { Cond } \\
\text { Conditions: Proprietary Information }\end{array}$} \\
\hline \multicolumn{11}{|c|}{ Radiological Activity (nCi) } \\
\hline & \multicolumn{2}{|c|}{ Pre-Soil } & \multicolumn{2}{|c|}{ Post-Soil } & \multicolumn{2}{|c|}{ Change } & \multicolumn{2}{|c|}{ Ligand } & \multicolumn{2}{|c|}{$\%$ Extracted } \\
\hline Extraction \# & $\mathrm{Pu}$ & Am & $\mathrm{Pu}$ & $\mathrm{Am}$ & $\mathrm{Pu}$ & $\mathrm{Am}$ & $\mathrm{Pu}$ & Am & $\mathrm{Pu}$ & Am \\
\hline 1 & 4708 & 24.8 & 3721 & 17.5 & 987 & 7.29 & 781 & 6.46 & & 26 \\
\hline
\end{tabular}


Table 7 Continued

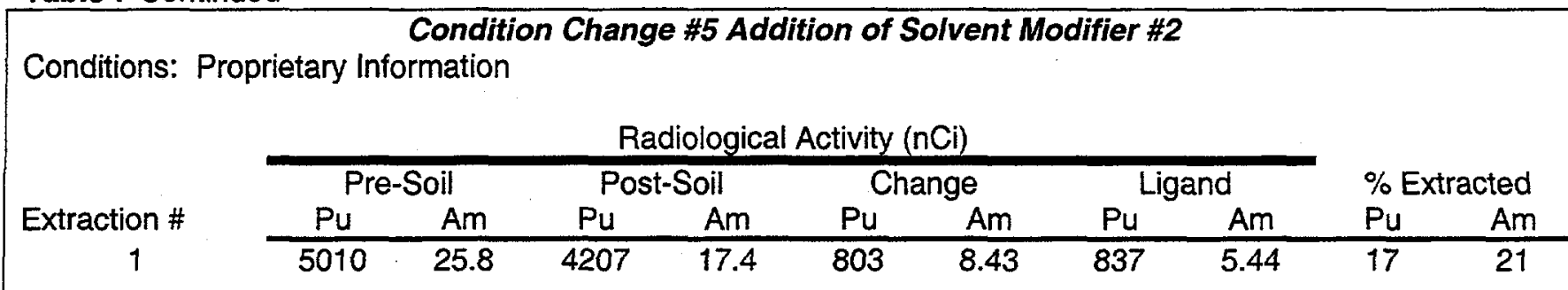

\section{Condition Change \#6 Higher Pressure}

Conditions: Proprietary Information

Radiological Activity ( $\mathrm{nCi}$ )

\begin{tabular}{cccccccccc}
\hline \multicolumn{2}{c}{ Pre-Soil } & \multicolumn{2}{c}{ Post-Soil } & \multicolumn{2}{c}{ Change } & \multicolumn{2}{c}{ Ligand } & \multicolumn{2}{c}{ Extracted } \\
$\mathrm{Pu}$ & Am & $\mathrm{Pu}$ & $\mathrm{Am}$ & $\mathrm{Pu}$ & $\mathrm{Am}$ & $\mathrm{Pu}$ & $\mathrm{Am}$ & $\mathrm{Pu}$ & $\mathrm{Am}$ \\
\hline 5076 & 26.2 & 2862 & 11 & 2215 & 15.2 & 1493 & 13.2 & 29 & 51
\end{tabular}

Condition Change \#7 Addition of Solvent Modifier \#1 and Increase Time

Conditions: Proprietary Information

Radiological Activity (nCi)

\begin{tabular}{ccccccccccc}
\hline \multicolumn{2}{c}{ Pre-Soil } & \multicolumn{2}{c}{ Post-Soil } & \multicolumn{2}{c}{ Change } & \multicolumn{2}{c}{ Ligand } & \multicolumn{2}{c}{$\%$ Extracted } \\
$\mathrm{Pu}$ & $\mathrm{Am}$ & $\mathrm{Pu}$ & $\mathrm{Am}$ & $\mathrm{Pu}$ & $\mathrm{Am}$ & $\mathrm{Pu}$ & $\mathrm{Am}$ & $\mathrm{Pu}$ & $\mathrm{Am}$ \\
\hline 4516 & 23.3 & 2153 & 6.84 & 2363 & 16.4 & 2961 & 15.8 & 66 & 68
\end{tabular}

Conditions: Proprietary Information

\section{Condition Change \#8 Change Ligand}

Radiological Activity ( $\mathrm{nCi}$ )

Extraction \#

\begin{tabular}{|c|c|c|c|c|c|c|c|c|c|}
\hline \multicolumn{8}{|c|}{ Radiological Activity ( $\mathrm{nCi}$ ) } & \multirow{2}{*}{\multicolumn{2}{|c|}{$\%$ Extracted }} \\
\hline & & Pos & & & & & & & \\
\hline $\mathrm{Pu}$ & $\mathrm{Am}$ & $\mathrm{Pu}$ & Am & $\mathrm{Pu}$ & $\mathrm{Am}$ & $\mathrm{Pu}$ & $\mathrm{Am}$ & $\mathrm{Pu}$ & $\mathrm{Am}$ \\
\hline 4437 & 22.9 & 934.7 & 1.5 & 3502 & 21.4 & 5316 & 21.5 & 80 & 93 \\
\hline
\end{tabular}


SFE of Soil B. Ligand-assisted supercritical fluid extractions were conducted on approximately $10 \mathrm{gm}$ per sample of soil B. The extraction radioanalytical results for the post-extracted soil and collected liquid extract (ligand) are found in Table 8. Two techniques which demonstrated greater than $60 \%$ removal on soil $A$ were then conducted and confirmed on soil $B$.

Table 8 LA-SFE Results for Soil B

Conditions: Proprietary Information

\section{Initial Extraction}

Radiological Activity ( $\mathrm{nCi}$ )

Extraction \#

Pre-Soil Post-Soil Change

1

2

\begin{tabular}{ccc}
$\mathrm{Pu}$ & $\mathrm{Am}$ & $\mathrm{Pu}$ \\
\hline 4871 & 25.9 & 4125 \\
5412 & 28.8 & 4142 \\
5500 & 29.2 & 4605
\end{tabular}
Am

$\mathrm{Pu} \quad \mathrm{Am}$

$18.6 \quad 1270$

$22.1 \quad 895$

$895 \quad 7.11$

\begin{tabular}{ccc} 
Am & \multicolumn{2}{c}{ Ligand } \\
\hline 5.40 & 1091 & Am \\
10.1 & 856 & 7.00 \\
7.11 & 1051 & 8.01
\end{tabular}

\% Extracted

\begin{tabular}{cc}
$\mathrm{Pu}$ & $\mathrm{Am}$ \\
\hline 22 & 34
\end{tabular}

$16 \quad 24$

$$
3
$$

(29.2


SFE of Soil C. Ligand-assisted supercritical fluid extractions were conducted on approximately $10 \mathrm{gm}$ per sample of soil $\mathrm{C}$. The radioanalytical results for the post-extracted soil and collected liquid extract (ligand) are found in Table 9. Two techniques demonstrated to be effective on soil A were then conducted and confirmed on soil $\mathrm{C}$.

Table 9 LA-SFE Results for Soil C

Conditions: Proprietary Information

\section{Initial Extraction}

Radiological Activity (nCi)

Extraction \#

Pre-Soil Post-Soil Change

1

2

$\frac{\mathrm{Pu}}{10851} 5 \mathrm{57}$

Am
$\mathrm{Pu}$

10372

$57.9 \quad 10517$

$\mathrm{Am}$

$55.3 \quad 8574$

41.5

54.6

9087

41.9

\begin{tabular}{c}
$\mathrm{Pu}$ \\
\hline 334 \\
1798 \\
1158
\end{tabular}

\begin{tabular}{ccc} 
Am & \multicolumn{2}{c}{ Ligand } \\
\hline 9.55 & 1545 & 1 \\
13.8 & 1496 & 13. \\
12.8 & 1154 & 11
\end{tabular}

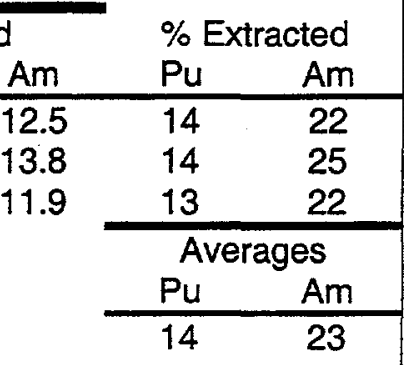

Conditions: Proprietary Information

Condition Change \#1 Increase Ligand Concentration 1 2

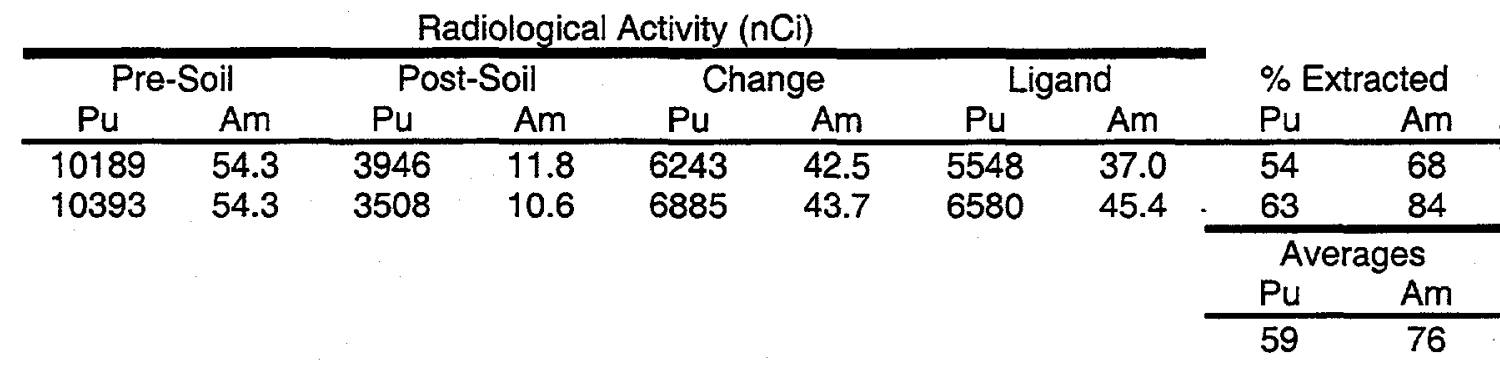

\section{Condition Change \#7 Addition of Solvent Modifier \#1 and Increase Time}

Conditions: Proprietary Information

\begin{tabular}{|c|c|c|c|c|c|c|c|c|c|c|}
\hline \multirow[b]{3}{*}{ Extraction \# } & \multicolumn{8}{|c|}{ Radiological Activity (nCi) } & & \\
\hline & \multicolumn{2}{|c|}{ Pre-Soil } & \multicolumn{2}{|c|}{ Post-Soil } & \multicolumn{2}{|c|}{ Change } & \multicolumn{2}{|c|}{ Ligand } & \multicolumn{2}{|c|}{$\%$ Extracted } \\
\hline & $\mathrm{Pu}$ & Am & $\mathrm{Pu}$ & $\mathrm{Am}$ & $\mathrm{Pu}$ & $\mathrm{Am}$ & $\mathrm{Pu}$ & $\mathrm{Am}$ & $\mathrm{Pu}$ & $\mathrm{Am}$ \\
\hline 1 & 10894 & 58.1 & 4967 & 13.8 & 5927 & 44.3 & 5158 & 42.5 & 47 & 73 \\
\hline \multirow[t]{3}{*}{2} & 9578 & 51.1 & 4603 & 13.6 & 4975 & 37.5 & 4190 & 35.5 & 44 & 69 \\
\hline & & & & & & & & & \multicolumn{2}{|c|}{ Ave } \\
\hline & & & & & & & & & $\mathrm{Pu}$ & $\frac{\mathrm{Am}}{\mathrm{T}}$ \\
\hline
\end{tabular}




\section{DISCUSSION}

The aqueous extraction data consistently showed that plutonium spiked into the RWMC soil samples partitioned into the residual fraction regardless of the chemical preparation technique used. It is unknown what the plutonium species is and further investigation is warranted. It is speculated that the plutonium is likely an oxide or hydroxide or an oxyhydroxide form of plutonium due to the $\mathrm{pH}$ of the RWMC soil and the method of slurry spiking used. It is unknown whether there is any degree of polymerization occurring; although, efforts are currently underway to identify the plutonium species present in the spiked samples. Americium partitioned primarily into the iron/manganese fraction with some remaining in the residual fraction. Other investigators studying americium, and using the identical aqueous extraction technique, indicate that the portion of americium partitioning into the organic phase is an incorrect reading and is rather an indication of incomplete dissolution of americium associated with the iron/manganese fraction (lbrahim). We also believe this to be the case for the RWMC soils due partially to the fact that the RWMC soils have very low organic content ( $0.39 \mathrm{wt} . \%)$.

The initial supercritical fluid extraction conditions gave relatively low extraction efficiencies. Modifications to those initial conditions proved that several factors may significantly influence the extraction process as was suspected. Process modifications were made and the $14 \%$ to $19 \%$ extraction efficiencies initially experienced jumped to the $60 \%$ to $80 \%$ level simply by making minor adjustments in the process conditions. Those results indicate that the extraction conditions are not currently optimized and can be optimized further. Thus, continued investigation is recommended. It should also be noted that some extraction parameter changes had little to no effect on extraction efficiency. Two of the best conditions found to date, although still not optimized, were then tried on soils $B$ and $C$. The results indicate that soil $A$ is likely the easiest to process whereas soil $C$ is second easiest and soil $B$ the most difficult. Those results indicate that some equilibrium between different plutonium species has occurred as a result of the different chemical preparations used on soils $A, B$, and $C$. What those changes are is unknown at this time; however, it is encouraging to see that extraction conditions were found relatively quickly which resulted in nearly $50 \%$ plutonium extraction from the difficult soil B matrix. Additional testing is currently underway and the second and third iteration experiments are expected to provide extraction efficiencies greater than $90 \%$ for soil A. Additional testing is also underway to confirm the extraction process on soils $\mathrm{B}$ and $\mathrm{C}$ to determine whether or not greater than $90 \%$ removal can be achieved for those soil chemistries.

\section{CONCLUSIONS}

These results indicate that the supercritical fluid extraction technique can effectively extract plutonium and americium from the spiked RWMC soil samples. The results also indicate that further study of extraction parameters is warranted as is an investigation of the extractability of different radionuclide species from RWMC soils. These results also indicate that the technique can move on to Treatability Study samples where process optimization can be achieved.

\section{THE PATH FORWARD}

The proposed plan is to advance the technique in size-of-scale and obtain several 250 gram to 500 gram quantities of Treatability Study samples from Pit 9, Pit 4 and Pit 10. Depending on a successful outcome to the Treatability Studies on various pit soils, further Treatability Studies would be performed and would involve a size-of-scale on the order of a 20 gallon to as large as a 55 gallon extraction vessel. From there, the process would eventually be scaled-up to an actual plant capable of nominally processing 20 tons of soil per day.

In addition to the engineering scale-up activities, BNFL has added support for the existing supercritical fluid research capabilities at the INEEL. Those research capabilities (personnel, equipment, facilities, etc.) will compliment and support the engineering scale-up tasks. 


\section{REFERENCES:}

1. LMITCO (Lockheed Martin Idaho Technologies Company), 1997, Revised Scope of Work for Operable Unit 7-13/14 Waste Area Group 7 Comprehensive Remedial Investigation/Feasibility Study, INEL95/0253.

2. Barnes, C.M., Garcia, K., Prendergast, J., 1995, Preliminary Development of Alternative Remediation Technologies and Identification of Data Needs for OU 7-13/14 Feasibility Study, INEL-95/199.

3. Arrenholz, D.A., Knight, J.L., 1991, A Brief Analysis and Description of Transuranic Wastes in the Subsurface Disposal Area of the Radioactive Waste Management Complex at INEL, EGG-WTD-9438

4. U.S. Patent $5,536,538$

5. Laintz, K.E.; Wai, C.M. Anal. Chem., 1992, 64(3), 311.

6. Fox, R.V., McMurtrey, R.D., Navratil, J., 1999, Proceedings of the International Solvent Extraction Conference, Barcelona, Spain.

7. Personal Communication from BNFL.

8. Smart, N.G.; Elashani, S.; Wai, C.M.; Carleson, T.E.; Fox, R.V., 1996, SPECTRUM 96, Seattle, WA.

9. The soil recipes were provided through a Personal Communication from BNFL and John Koltz, DOEID.

10. Tessier, A, Campbell, P.G.C., Bisson, M., Anal. Chem., 1979, 51(7) 844. 